\title{
Grasping the social through movies
}

\section{Nilgün Fehim Kennedy , Nazli Şenses \& Pelin Ayan}

To cite this article: Nilgün Fehim Kennedy , Nazli Șenses \& Pelin Ayan (2011) Grasping the social through movies, Teaching in Higher Education, 16:1, 1-14, DOI: 10.1080/13562517.2010.507305

To link to this article: https://doi.org/10.1080/13562517.2010.507305

央 Published online: 17 Jan 2011.

Submit your article to this journal

山ll Article views: 467

Citing articles: 10 View citing articles 5 


\title{
Grasping the social through movies
}

\author{
Nilgün Fehim Kennedy*, Nazli Şenses and Pelin Ayan \\ Department of Political Science, Bilkent University, Ankara, Turkey \\ (Received 30 August 2009; final version received 17 May 2010)
}

In Turkey, one of the major challenges that university education faces is the indifference of young people towards social issues. The aim of this article is to contribute to the practice of critical pedagogy by proposing that showing movies is an important critical teaching method with the power both to give pleasure to the students and to develop their interest in crucial social issues. To support our argument, we showed three movies to students taking Sociology and Social Psychology courses in three successive academic terms on the topics 'the death penalty', 'gender equality' and 'prejudice'. Analysing the essays which the students were asked to write on these movies, we observed growing interest and an increase in critical thinking on the issues in question. We then conducted a survey to test this change quantitatively. The results indicate that showing movies is very influential in helping students to develop an interest and critical perspective.

Keywords: movie showing; interest development; critical perspective; critical teaching; sociology; social psychology

\section{Introduction}

Young people under the age of 25 make up $43.74 \%$ of the population of Turkey. Prior to the 1980 military coup, youth - university youth in particular - was politicised and took a close interest in current affairs. However, the 1980 military coup not only repressed this generation (including the use of torture and capital punishment) but also created a new type of apolitical youth, the knowledge and culture of which were limited to consumption culture and which paid no need to others. This new youth would be known as the 'Özal Youth' after the name of Prime Minister (later President) Turgut Özal, the architect of the neo-liberal policies implemented following the coup.

In a recent study conducted by Bahçeșehir University and the Ministry of Foreign Affairs of the UK, 1715 respondents were identified through probability sampling among the population above the age 15, and interviewed face-to-face on 'Radicalism and Extremism'. The survey was carried out in 34 provinces of Turkey in 2009. The findings of the research indicated that, as a neighbour, $72 \%$ did not want an alcohol drinker, $67 \%$ did not want a couple living out of wedlock, $35 \%$ a family whose daughter wore shorts, $75 \%$ someone who did not believe in god, $52 \%$ a Christian and 64\% a Jew. Among the respondents, $84 \%$ thought that a woman should get permission from her husband to work, and $85 \%$ thought it proper that a woman should seek the permission of her husband in order to go somewhere on her

*Corresponding author. Email: nilgunke@bilkent.edu.tr 
own (principal researcher, Y1lmaz Esmer on daily newspapers Cumhuriyet, Milliyet, and Zaman 31 May 2009). In a secular country, those who thought that a woman who had committed adultery should be stoned to death formed $22 \%$ - a frighteningly high figure, especially when coupled with the rise in 'honour' killings throughout the 2000s. Another eye-catching feature of the study was that the above percentages were highest among the 15-18 age group.

Research (Zeylan 2007) conducted on the identity of educated youth aged 15-24 in Istanbul also points to the rise of conservative values and depolitisation among youth. Among educated young people, only 18.3\% were found to be interested in political issues. Those positioning themselves on the conservative side of the political spectrum accounted for $43.7 \%$, while $25 \%$ were undecided (Zeylan 2007, 146-7). Other studies (Erdem-Artan 2005; Kazgan 2002, 2006; Pultar 2008) show that as young people get older and their level of education increases, their tendency to conservatism and intolerance declines. Therefore, one might expect university education to develop social awareness, tolerance and critical thinking.

However, entering university is difficult, and for many years before entering university, the education (and indeed the lives) of most students has been dominated by preparation for a university entrance examination consisting of multiple choice questions. Many freshmen then have difficulty in adapting to university education, and display lack of focus, boredom and superficial points of view.

We may conclude that classes with a social content taken during university education are particularly important for developing students' interests and critical thinking in social affairs. Yet, what is important is to find adequate teaching methods through which these students can develop a further interest in national and international affairs.

\section{The purpose of the study}

As a lecturer who has been teaching Sociology and Social Psychology to students from the above profile and two teaching assistants at Bilkent University, we have adopted 'showing movies' as a teaching method in order to develop student interest in serious social issues of Turkey - gender equality, prejudice and the death penalty - and help to encourage critical agency in society. Thus, the main purpose of this study is to combine the strength of showing movies as a teaching method with the practice of critical pedagogy, specifically critical teaching, which is deeply rooted in theory, rather than practice.

The justification for using 'movies' as a teaching method derives, in our case, from the results of previous research in the field. Showing movies has been seen as facilitating the learning process among students in many disciplines including political science, American studies, psychology, anthropology, organisational management and neuroscience (Boyatzis 1994; Forbes and Smith 2007; Funderburk 1978; Kranzdorf 1980; Mallinger and Rossy 2003; O’Meara 1976; Roberts 2003; Ruby 1976; Sanchez 1976; Smith 2009; Wiertelak 2002).

Many other studies have shown that showing popular movies focusing on societal concerns is a useful tool in improving students' attention to the subjects taught in classes as well as to current sociological events (Boyatzis 1994; Deighton 1971, 12; Maynard 1971; Roberts 2003; Smith 1973). Given the effectiveness of this method 
outlined in the literature, the present study also argues that 'showing movies' can be treated as a decisive technique in higher education to generate critical agents.

This approach is also in line with the concerns of critical pedagogues who constantly emphasise that teaching as a practice must 'take the students beyond the world they already know, in a way that does not insist on a particular fixed set of altered meanings...' (Giroux 2007, 3). In other words, 'critical teaching should be creative, multi-perspectival, culturally relevant, emotionally responsive, political, contextual, and psychological in mood and orientation' (Weiner 2007, 66). On the other hand, although critical pedagogy aims to challenge the conservative sociopolitical domain and the imposed official knowledge (Apple 1995, 2000; McLaren and Kincheloe 2007), it is too entrenched in theory. In other words, little attention is paid to how to achieve this goal in practice. And yet 'one of the central components of critical pedagogy is to challenge and eventually alter oppressive structural constraints in a practical way' (Kanpol 1999, 185, emphasis added). Thus, this study, in a way, combines the strength of showing movies as a teaching method with one of the major aims of critical pedagogy, which is to be more productive in a practical sense.

Another defence of 'showing movies' as a method for critical teaching derives from our highly capital-driven, conservative world. Movies - along with television, video games, music and the Internet - are regarded as one of the most effective tools of popular culture in giving pleasure to its target group and creating the phenomenon of depolitisation (Kincheloe 2007, 31). However, we argue that the power of pleasure in movies can also be utilised for the reverse purpose, which is to create political consciousness and social awareness among the target group. For instance, Giroux $(2002,8)$ stresses that 'theorizing masculinity in American society becomes more meaningful and concrete when taken up within a film such as Fight $C l u b$, especially since many students identify with the film and only after seeing and talking about it as part of a critical and shared dialogue do they begin to question critically their own investment in the film'. Hooks $(1996,2)$ notes a similar observation, stating that:

... it has only been in the last ten years or so that I began to realize that my students learned more about race, sex, and class from movies than from all the theoretical literature I was urging them to read. Movies not only provide a narrative for specific discourses of race, sex, and class, they provide a shared experience, a common starting point from which diverse audience can dialogue about these charged issues.

In order to support the arguments outlined above, this study has adopted the following methodology. After the theoretical lecture and debate, we showed a movie with a social content in class, and then the students were asked to write an essay relating the theoretical knowledge of the course with the movie. In the following sections we share the results of this process by analysing the student essays and a student survey that evaluates 'showing movies' as a teaching technique.

\section{Research universe}

The research took place at Bilkent University which was established in 1984 as the first non-profit private university of Turkey, offering programmes both in social 
sciences and engineering. This study involved students who took Introduction to Sociology 101 (SOC 101) and Introduction to Social Psychology 102 (PSYC 102) at Bilkent between the spring 2008 and spring 2009 academic terms. These two courses are taught to freshmen during their first and second semesters, respectively. They are compulsory for students in certain departments and available as electives for certain others. SOC 101 introduces topics such as: socialisation and interaction; sex and gender; racial and ethnic identities; stratification, class and status; communication and media; globalisation; politics and power; and inequality, poverty and wealth. PSYC 102 covers topics such as: social cognition; social perception; the need to justify actions; attitudes and attitude change; conformity; group processes; aggression; and prejudice.

Due to the vast number of students taking these courses both as elective and as compulsory courses, the number of students in each section is typically between 45 and 60 . These are also the only courses at Bilkent which bring together students from a wide variety of departments. This departmental diversity creates a non-homogenous population.

\section{The research process}

The research process adopted for this study comprises two main stages: the inquiry stage and the survey stage. In the inquiry stage, as the instructor and teaching assistants in SOC 101 and PSYC 102, we aimed to find out whether a level of consciousness could be observed among the students through showing movies. In order to meet this aim, we showed three movies to 546 students in three successive academic terms. In spring 2008, after lectures on Attitude and Attitude Change, we showed A Short Film About Killing (directed by Kieslowski in 1988) to PSYC 102 students; in fall 2008, following lectures on Gender, Sex and Sexuality we showed Ten (directed by Kiarostami in 2002) to SOC 101 students, and in spring 2009, after lectures and debates on Prejudices, we showed Hotel Rwanda (directed by George in 2004) to PSYC 102 students. Of these three films, only Hotel Rwanda had been watched by some students when it was shown in cinemas. We observed that students were affected by the films and reacted vocally during the viewings.

The reason for choosing these movies is that the themes they refer to have certain significance for the conventional mentality of the Turkish society. First, gender inequality is seriously apparent in many spheres from the political representation of women to honour killings. Second, capital punishment, although it has been abolished, still has a serious support base in society; for many people, the customary phrase 'hang a few of them - see if they do it again' represents a solution to social problems. Finally, prejudice against ethnic groups is one of the most important problems of Turkey, surfacing mostly around the Kurdish issue. Therefore, through these movies, we aimed to create awareness among students who were indifferent to these very critical issues of Turkey.

\section{Student essays ${ }^{1}$}

In order to observe the effect of movies on the critical consciousness of the students, they were asked to write short essays, shortly after showing the movies, in which they discussed the relevant theories taught in the course through what they observed in 
the movies. In spring 2008, 183 students wrote essays on A Short Movie about Killing, in which they were asked to elaborate on how the film had affected their attitude towards the death penalty. In fall 2008, 236 students wrote essays on Ten, in which they were asked to point out examples of patriarchy and inequalities between men and women. In spring 2009, 126 students wrote essays on Hotel Rwanda, in which they were asked to discuss ethnic prejudice by utilising the prejudice between the Hutus and the Tutsis. In all the essays, students were obliged to support their ideas with the theoretical explanations taught in class lectures.

Analysing the essays, we have concluded that movies lead the students to develop an interest in the subjects they study and to write more critical papers. Below we give some excerpts from the essays to support our findings in the inquiry stage. The exact wordings of the students are preserved in all the excerpts without correcting the grammatical errors.

On the movie Ten, one of the students starts her essay by showing her admiration for the movie and how it helped her understand the critical importance of gender issues:

Ten is a great and humanistic movie to show all women's problems in life and to make women conscious individuals by showing the truths although they are bitter. It states that domestic division of labour of Marxist-feminist approach can still seen although years passes by.

Another student in relation to gender inequality and patriarchy, states:

Amin [the woman's son] doesn't criticize his father ... since Amin, like nearly all people in the world, perceives that all the housework and child care is the responsibility of mothers.

On the other hand, another student came up with a rather subtle example of patriarchy and wrote:

Also the scene where the boy puts his hands on his ears and just starts to sing while the woman is trying to explain her situation is really very significant because it stands for patriarchy's underestimation and ignorance of women.

Therefore, the movie not only helped the students to understand social concepts better; but it also led them towards having more critical perspectives as, we believe, the movie powerfully aroused their interest in the subject.

The emergence of interest and a critical point of view were also apparent within the essays in which students were asked to write on A Short Film About Killing and how it had affected their attitudes towards capital punishment. A great majority of the essays show that the movie had led the students to think more (and become more ambivalent towards) whether or not it was 'correct' to punish a violent criminal act by capital punishment. In relation to that, a student wrote the following:

When I saw the movie I thought that the first important scene was the murder scene and the other one is Jacek's [the murderer] death by capital punishment. Although I was angry with him in the first scene, I was sorry about him and did not support his punishment in the second scene... I hate, fear and feel sad about capital punishment again and again. 
Another student stated:

Kieslowski's film is very persuasive to change the attitude about execution. For example, in the film when the murderer was about to kill the taxi driver, his shoe fell and he peed because of fear. And when the state was about to kill the murderer, the same things happened to the murderer. There is a clear parallel between two types of killing. The film makes us to ask that question; what is the difference between murder and capital punishment?

The movie Hotel Rwanda, on the other hand, developed the students' interest in issues of ethnic discrimination. To illustrate this point one student wrote:

We can also see the prejudice of Europeans towards African people in the film. In the film, European countries watched the cruelty, genocide in their TVs and didn't intervene it. Maybe they don't kill the Tutsis by their own hands, but they close their eyes and ears as the journalist in the film said, as a proof of modern racism.

Another student also wrote that:

As it is observed in the movie Hotel Rwanda there is an apparent example of discrimination between people... Of course this discrimination did not occur coincidently amongst these people; limited resources made these groups enemies of each other and increased the level of prejudice against each other as the realistic conflict theory states.

In another essay written on Hotel Rwanda, a student concluded his essay as follows:

What was experienced in Rwanda is just one example of ethnic prejudice and discrimination in the world. Darfur must not be forgotten. At least three generations have been lost there. It is kept saying that this crime must come to an end but same events repeat themselves in the world history. Communication and dialogue must be used as a key in solving such crimes.

To sum up, these quotations from the students' essays indicate that students start developing a critical perspective on these topics because they get more interested after seeing the movies. In other words, one could argue that movies help the students build critical perspectives on the 'social' through interest development on sociological topics. Additionally, through these movies, they have the chance to discuss certain theoretical frameworks and concepts in relation to 'real-life' settings, and hence acquire a new meaning for these frameworks and concepts in practical terms.

\section{Student surveys}

Observing that the student responses to the essay questions showed a certain level of consciousness in three critical subject matters (death penalty, gender (in)equality and prejudice); in the second stage of the research, we decided to conduct a survey among the students to numerically test the ratio of students that have developed an interest and critical perspective on these issues.

Before the final exam of the Social Psychology course in spring 2009, we distributed a 14-question survey form (see the Appendix) to the students. We told them the purpose of the research and requested them to answer the questions anonymously. It must be noted that among a total of 546 students who had seen at least one movie in 
the last three academic terms, we were able to conduct the survey only among the students who took PSYC 102 in spring 2009. However, most of the students had watched at least two of the films, as most of them had taken two separate classes (Sociology and Social Psychology) from the same instructor. Among the 126 students who were taking this course 112 took the survey.

As McIntyre $(2005,105)$ states, 'one of the sampling strategies in non-probability sampling techniques is judgement sampling. Sometimes called purposive sampling, this sort of sampling requires the researcher to use his or her best judgement to select a sample. Judgement sampling makes sense when the researcher has a great deal of knowledge about the population of interest'. Given that one of the authors has been an instructor in the same university for eight years, she may be supposed to have 'a great deal of knowledge about the population of interest' and accordingly to be in a position to make judgements in selecting a sample. For this reason, although we were not able to reach all of the students who had taken SOC 101 and PSYC 102 in the first two terms; we believe that the results of the survey would not be significantly different if we had reached them all. This is because we had observed approximately the same level of interest development and consciousness in student responses to essay questions in all of the three consecutive academic terms. Thus, the excerpts from student essays may be considered to complement the findings of the survey.

\section{Survey results: the assessment of 'showing movies' as a teaching method}

In terms of the students' own perceptions, the survey results show that 61 students thought that they had developed a high level of critical perspective on social issues after taking SOC 101 and PSYC 102, while 44 students indicated that they had developed a somewhat critical perspective. Only seven students indicated that they had not developed a critical perspective at all.

In order to compare the impact of showing movies with other teaching methods, the students were asked to rate specific teaching methods from 'very useful' to 'not useful at all' in learning the concepts and theories of Sociology and Social Psychology. The student ratings of the various teaching methods are illustrated in Figure 1.

Meanwhile, independent of the other teaching methods, when the students were asked to what extent watching movies helped them to understand certain topics (such as 'prejudice', 'attitudes' and 'gender equality'), 78 of them indicated that movies were very useful and 34 indicated that they were somewhat useful. None of the students indicated that watching movies was not useful at all. Thus, the students who responded to the survey thought that watching movies in Sociology and Social Psychology courses helped them to understand certain themes better.

The survey also included an open-ended question asking students to give their opinions about the extent to which movies are necessary for understanding the themes of the course. Among the students who responded to this question, a great majority found movies necessary. Only six out of 42 stated that movies are not necessary for learning the course topics. Three main arguments recurred frequently in the responses given to the open-ended question by students who found movies necessary.

First, movies are found necessary because students think that they are not as boring as their textbook but are fun, interesting and easy to understand. According to student A, 'Movies always make the topic clearer because it's visual. However, 


\section{Listening to the lecture $\quad$ Class discussion $\quad$ Watching a movie}

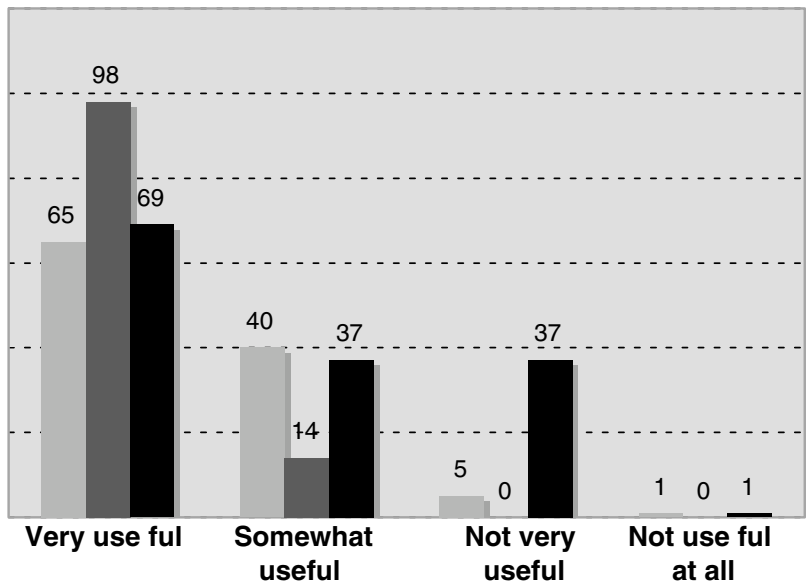

Figure 1. Student rating of 'teaching methods'.

books are always boring because they just give theoretical definitions'. In similar fashion, student B stated that 'watching movies is the best way to understand the course topic. It is not boring like reading the course book'.

Second, students think that movies establish a link between real life and the textbook. In other words, they think that they could 'observe' what they have learned from the textbook/lectures in the movies. Here are some excerpts:

Student C: They provide another view. It becomes more tangible, rather than being abstract.

Student D: It's very helpful to relate issues with real life.

Student E: Thanks to movies I could observe the situations.

Third, students find movies necessary because they think that they learn the topics better and they do not forget what they have learned after they see a movie on that topic. Student F stated that: 'It is more effective when we both watch and read the materials about the subjects. This helps us not to forget about them'. Student G stated that 'movies attract more attention and from films I can learn concepts more easily'.

With respect to interest development, 88 of the students indicated that after taking Sociology and Social Psychology classes they had started paying more attention to the TV news, newspaper articles and discussions about issues of 'prejudice', 'attitudes' and 'gender relations'. Hence, it is clear that these courses do also raise the interest of the most of the students in real social issues.

The students were also asked to what extent watching a movie made them more interested in the topics covered in the Sociology and Social Psychology classes. Figure 2 illustrates these results.

According to these results, the effect of watching movies in raising the interest of the students towards the disciplines of Sociology and Social Psychology is not negligible; only 23 out of 112 respondents indicated that watching movies did not make them interested in these subjects. 


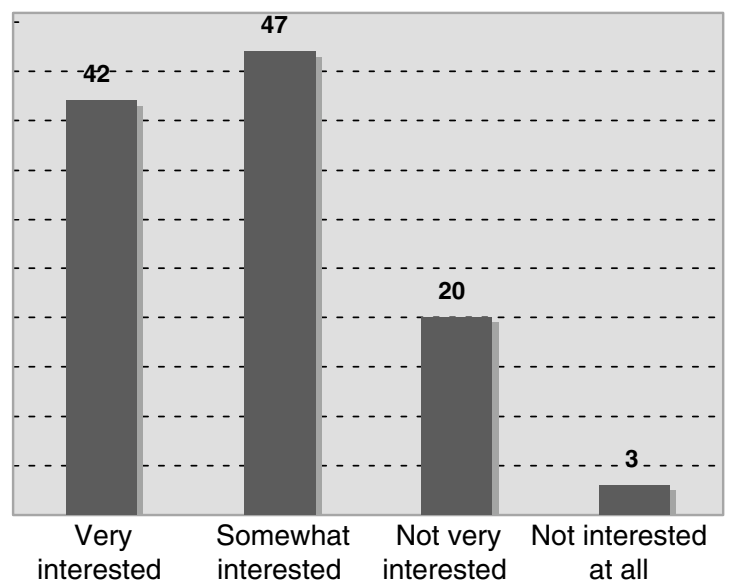

Figure 2. How interested have you become after movies?

It is important to understand whether 'watching movies' increased the level of interest of the students who were only 'somewhat interested' or 'not very interested' in Sociology and Social Psychology to begin with. Figure 3 illustrates the changes among the students in this respect.

According to Figure 3, among the 42 who responded that watching movies made them 'very interested' in Sociology and Social Psychology, 16 indicated that they were already very interested in these disciplines. Therefore, watching movies did not affect these 16 students. Yet 26 out of these 42 students had become 'very interested' in the disciplines only after watching movies. Out of these 26 students, 23 of them were previously 'somewhat interested' and three of them were previously 'not very interested'. In other words, the level of interest of 23 students showed a positive change and that of three students a big positive change. Among the students who

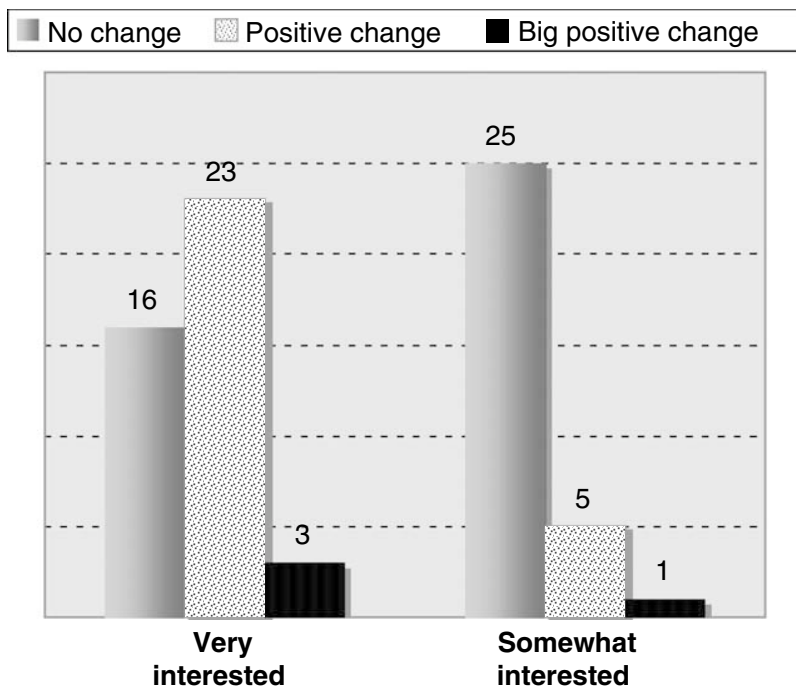

Figure 3. Effect of watching movies on the interest development of the students. 
were 'somewhat interested' in Sociology and Social Psychology, 25 indicated that they were already 'somewhat interested' in the disciplines before 'watching movies'; in other words, 'watching movies', again, had no effect on these 25 students. However, five of the students were previously 'not very interested' and became 'somewhat interested' only after having watched the movies, indicating a positive effect. One of the 'somewhat interested' students was previously 'not interested at all', pointing to a big positive effect.

In summary, the results show that in total 32 students $(23+3+5+1)$ out of 112 developed their interests in these disciplines after watching movies.

It is evident that the impact on interest development and critical thinking is not tremendous. Watching movies helps only a certain number of students to better grasp the meaning of the 'social'. These results point to some important clues about why the movies enhance the critical learning of a number of students and not the others; the enhancement of critical perspectives through movies is closely associated with the degree of interest development in the subjects that the students study. Thus, critical learning goes hand in hand with interest development.

To sum up, based on an evaluation of the survey results we argue that 'movie showing' as a method of teaching triggers the emergence of critical perspective among students. In class discussions before showing the movies, most of the students were indifferent and had clichéd ideas about the topics in question. When we were evaluating their essays we were surprised to see a growing degree of awareness in most of them. Although, this change on the part of the student might seem minor, it must be considered within the context of a society in which conditions have encouraged youth to become apolitical and indifferent to major social issues.

\section{Concluding remarks}

The purpose of this study was to contribute to one of the major practical fields of critical pedagogy: critical teaching. We have depicted the impact of showing movies on the teaching of certain issues in Sociology and Social Psychology and argued that 'showing movies' is an important tool for teaching in higher education in order to contribute to the development of critical agency in a conservative society. As a matter of fact, analysis of the student surveys and essays indicates that showing movies actually helps the students to build critical perspectives on subjects with social content by arousing their interests on these topics.

Movies have been seen as agents of depolitisation, providing only pleasure. But why not use the power of pleasure, the very strategic tool of corporations, for exactly the opposite purpose, which is to create political consciousness and social awareness? This study reveals that movies can, in fact, create a counter effect and develop awareness among students on social and political matters when used as a method for critical teaching by developing their interest in these matters.

Although, showing movies in higher education has these merits, we have also experienced certain disadvantages which must not be ignored. First, when the students do not like a movie shown for teaching purposes, it is quite possible that they will not be able to relate what they have learned in class to the movie. Some students did report their dislike of the movies. One student, for instance, thought that Hotel Rwanda was too violent. The student explained this view in the open-ended question as follows: 'The movie is an aggressive one. Nobody should be made to watch such a movie [Hotel 
Rwanda]. It should not be obligatory'. A second disadvantage of showing movies is that we cannot always use the movies most suitable for the topics in question, as we restrict ourselves to movies which are not so violent or erotic that they cannot be shown in an undergraduate course without becoming too unconventional. Finally, analysing the results of the surveys, we have also recognised the need for class discussion of the major points that the movies address. While answering the open-ended question one student wrote: 'The theme of the film should be discussed in the lesson after watching it'. So in our case we could have increased the impact of the movies in developing understanding if we had held a class discussion after, or before, asking students to write their essays. Despite these few drawbacks, we strongly believe that the benefits of showing movies in higher education must be given due recognition in societies with a high population of depoliticised youth.

\section{Note}

1. Student essays could be provided from the corresponding author on request.

\section{Author's Note}

Pelin Ayan has moved from the Bilkent University after this research was conducted. Ayan is currently a faculty member in the School of International Relations and Diplomacy at the Anglo-American University in the Czech Republic.

\section{References}

4 kişiden 3'ü 'içki içen komşu' istemiyor [3 out of 4 do not want an 'alcohol drinker neighbour']. Milliyet, May 31 2009, Today's section, Ankara edition.

Apple, M. 1995. Education and power. New York: Routledge.

Apple, M. 2000. Official knowledge: Democratic knowledge in a conservative age. New York: Routledge.

Boyatzis, C. 1994. Using feature films to teach social development. Teaching Psychology 21: 99-101.

Deighton, L.C., ed. 1971. The encyclopedia of education. 4 vols. New York: Macmillan.

Erdem-Artan, İ. 2005. Üniversite gençligi değerler araştırması [College youth values research]. İstanbul: TESEV.

Farklılıklara kapalı toplum [Society closed to diversity] Cumhuriyet. May 31 2009, Today's section, Ankara edition.

Forbes, B., and J.E. Smith. 2007. The potential of Erin Brockovich to introduce organizational behavior topics. Organization Management Journal 4: 207-18.

Funderburk, C. 1978. Politics and the movie. Teaching Political Science 6: 111-6.

Giroux, H. 2002. Breaking in to the movies: Film and the culture of politics. Malden, MA: Blackwell.

Giroux, H. 2007. Democracy, education, and the politics of critical pedagogy. In Critical pedagogy: Where are we now? ed. P. McLaren and J. Kincheloe, 1-5. New York: Peter Lang.

Hooks, B. 1996. Reel to real: Race, sex, and class in the movies. New York: Routledge.

Kanpol, B. 1999. Critical pedagogy: An introduction. 2nd ed. Westport, CT: Bergin and Garvey.

Kazgan, G., ed. 2002. Kuştepe Gençlik araştırması [Kuştepe youth research]. İstanbul: İstanbul Bilgi Üniversitesi Yayınlart.

Kazgan, G., ed. 2006. Istanbul Gençliği: Gençlik değerleri araştırması 2004 [The İstanbul youth: Youth values survey 2004]. İstanbul: Bilgi Üniversitesi Yayılarl.

Kincheloe, J. 2007. Critical pedagogy in the twenty-first century. In Critical pedagogy: Where are we now? ed. P. McLaren and J. Kincheloe, 9-42. New York: Peter Lang . 
Kranzdorf, R.I. 1980. Political science film courses: More than meets the eye. Teaching Political Science 7: 345-52.

Mallinger, M., and G. Rossy. 2003. Film as a lens for teaching culture: Balancing concepts, ambiguity, and paradox. Journal of Management Education 27, no. 5: 608-24.

Maynard, R.A. 1971. The celluloid curriculum: How to use movies in the classroom. New York: Hayden.

McIntyre, L. 2005. Need to know: Social science research methods. New York: McGraw Hill.

McLaren, P., and J.L. Kincheloe, eds. 2007. Critical pedagogy: Where are we now? New York: Peter Lang.

O'Meara, P. 1976. The use of full-length commercial films in political science undergraduate education. Teaching Political Science 3: 215-21.

Pultar, E. 2008. Biz Kimiz? KONDA Toplumsal Yapı Araștırmasında Gençler [Who are we? Youth in the KONDA research on societal structure]. In Türkiye'de Gençlik CCalışmaları ve Polilikarı [The youth work and policies in Turkey], ed. N. Yentürk, Y. Kurtaran and G. Nemutlu, 259-285. İstanbul: İstanbul Bilgi Üniversitesi Yayınları.

Roberts, L. 2003. Using feature films to teach poverty. Journal of Teaching in Marriage \& Family 3, no. 1: 47-70.

Ruby, J. 1976. Anthropology and film: The social implications of regarding film as communication. Quarterly Review of Film Studies 1: 436-45.

Sanchez, J.M. 1976. Hollywood comes to class: A course on the American political film. Teaching Political Science 4: 93-100.

Smith, D.D. 1973. Teaching introductory sociology by film. Teaching Sociology 1: 48-61.

Smith, G. 2009. Using feature films as the primary instructional medium to teach organizational behavior. Journal of Management Education 33, no. 4: 462-89.

Türkiye'de 'mahalle baskıs1' yok [There is no 'neighbourhood pressure' in Turkey] Zaman. May 31 2009, Today's section, Ankara edition.

Weiner, E. 2007. Critical pedagogy and the crisis of imagination. In Critical pedagogy: Where are we now? ed. P. McLaren and J. Kincheloe, 57-77. New York: Peter Lang.

Wiertelak, E.P. 2002. And the winner is: Inviting Hollywood into the neuroscience classroom. The Journal of Undergraduate Neuroscience Education 1, no. 1: A4-A17.

Zeylan, U.S., ed. 2007. Eğitimin değeri ve gençlik [The value of education and youth]. İstanbul: İstanbul Bilgi Üniversitesi Yayınları.

\section{Appendix. Student survey}

1. The movies that I have seen in my Sociology and/or Social Psychology classes have helped me to understand the themes of 'prejudice', 'attitudes' and 'gender equality' in general.
( )
( )
( )
( )
Very
Somewhat
Not very
Not at all

2. Watching movies in Sociology and/or Social Psychology class(es) helps me understand the concepts and theories better.
( )
Very
Somewhat
Not very
Not at all

3. In learning the concepts and theories of Sociology and/or Social Psychology, I rate the following teaching methods as follows:

Listening to

the lecture
Very useful

Somewhat useful
( )
Not very useful
Not useful at all 


$\begin{array}{llll}\text { Class } & \text { ( ) } & \text { ( ) } & \text { ( ) } \\ \text { discussion } & & & \text { ( ) } \\ \text { Watching a } & \text { ( ) } & \text { ( ) } & \text { ( ) }\end{array}$

4. I believe I have developed a critical perspective of Prejudice/Attitudes/Gender relations after learning these themes in my Sociology and/or Social Psychology class(es).
( )
( )
( )
( )
Very
Somewhat
Not very
Not at all

5. Watching a movie in the course aroused my interest in studies related to Prejudice/Attitudes/ Gender.
( )
( )
( )
( )
Very
Somewhat
Not very
Not at all

6. Watching movies in Sociology and/or Social Psychology class(es) make(s) me more interested in these disciplines.
( )
( )
( )
( )
Very
Somewhat
Not very
Not at all

7. The courses, in which we learn the course material through watching movies, are more interesting than the courses in which we do not see such movies.
( )
( )
( )
( )
Very
Somewhat
Not very
Not at all

8. Sociology and/or Social Psychology class(es) was/were the only class in which I was asked to understand the concepts and theories by watching a movie.
( ) Yes
( ) No

9. If I rate all the courses I took this semester from the most interesting to the least interesting, Sociology and/or Social Psychology course(s) will be rated as.
( )
( )
( )
( )
Very
Somewhat
Not very
Not at all
interesting
interesting
interesting
interesting

10. I was already interested in the Sociology and/or Social Psychology topics before I took the course(s) this year.
( ) Yes
( ) $\mathrm{No}$

11. I have become interested in Sociology and/or Social Psychology topics after I took these course(s).
( ) Yes
( ) No 
12. After taking the Sociology and/or Social Psychology class(es), I have started paying more attention to the TV news, newspaper articles and discussions in my social environment about sociological issues (such as prejudice, attitudes and gender relations).
() Yes
( ) No

13. What are your personal opinions about watching movies in Sociology and/or Social Psychology class(es)? To what extent are they necessary or contributive to you in learning the themes in your course books?

14. Did the Sociology and/or Social Psychology class(es), in general, help you to understand the sociological issues and problems in Turkey? In what way? 